BMJ Open Diabetes Research \& Care

\title{
Periodontitis as a possible early sign of diabetes mellitus
}

\author{
Wijnand J Teeuw, ${ }^{1}$ Madeline X F Kosho, ${ }^{1}$ Dennis C W Poland, ${ }^{2}$ \\ Victor E A Gerdes, ${ }^{3,4}$ Bruno G Loos ${ }^{1}$
}

To cite: Teeuw WJ, Kosho MXF, Poland DCW, et al. Periodontitis as a possible early

sign of diabetes mellitus. BMJ Open Diabetes Research and Care 2017;5:e000326. doi:10.1136/bmjdrc-2016000326

\section{- Additional material is} available. To view please visit the journal online (http://dx. doi.org/10.1136/bmjdrc2016-000326).

Received 14 September 2016 Revised 10 December 2016 Accepted 17 December 2016

\section{(1) cosshark}

\author{
${ }^{1}$ Department of \\ Periodontology, Academic \\ Centre for Dentistry \\ Amsterdam (ACTA), \\ University of Amsterdam and \\ VU University, Amsterdam, \\ The Netherlands \\ ${ }^{2}$ Department of Clinical \\ Chemistry, MC Slotervaart, \\ Amsterdam, The Netherlands \\ ${ }^{3}$ Department of Vascular \\ Medicine, Academic Medical \\ Center (AMC), University of \\ Amsterdam, Amsterdam, The \\ Netherlands \\ ${ }^{4}$ Department of Internal \\ Medicine, MC Slotervaart, \\ Amsterdam, The Netherlands
}

Correspondence to Dr Wijnand J Teeuw;

W.Teeuw@acta.nl

\section{ABSTRACT}

Objective: The early diagnosis of (pre)diabetes mellitus is essential for the prevention of diabetes complications. It has been suggested that gum disease (periodontitis) might be an early complication of diabetes and may be a useful risk indicator for diabetes screening. Therefore, a dental office could be a good location for screening for (pre)diabetes in patients with periodontitis using a validated glycated hemoglobin (HbA1c) dry spot analysis.

Research design and methods: $A$ total of 313 individuals from a university dental clinic participated. From 126 patients with mild/moderate periodontitis, 78 patients with severe periodontitis and 109 subjects without periodontitis, $\mathrm{HbA} 1 \mathrm{c}$ values were obtained by the analysis of dry blood spots. Differences in mean $\mathrm{HbA1c}$ values and the prevalence of (pre)diabetes between the groups were analyzed.

Results: The mild/moderate and severe periodontitis groups showed significantly higher $\mathrm{HbA1c}$ values $(6.1 \% \pm 1.4 \%(43 \mathrm{mmol} / \mathrm{mol} \pm 15 \mathrm{mmol} / \mathrm{mol})$ and $6.3 \%$ $\pm 1.3 \%(45 \mathrm{mmol} / \mathrm{mol} \pm 15 \mathrm{mmol} / \mathrm{mol})$, respectively) compared with the control group $(5.7 \% \pm 0.7 \%$ (39 mmol/mol $\pm 8 \mathrm{mmol} / \mathrm{mol}$ ), $\mathrm{p}=0.003$ ). In addition, according to the American Diabetes Association (ADA) guidelines for diagnosis, there was a significant overrepresentation of subjects with suspected diabetes (23\% and $14 \%$ ) and pre-diabetes ( $47 \%$ and $46 \%$ ) in the severe periodontitis group and mild/moderate periodontitis groups, respectively, compared with the control group ( $10 \%$ and $37 \%, p=0.010)$. Notably, $18.1 \%$ of patients with suspected new diabetes were found among subjects with severe periodontitis compared with $9.9 \%$ and $8.5 \%$ among subjects with $\mathrm{mild} /$ moderate periodontitis and controls, respectively $(\mathrm{p}=0.024)$.

Conclusions: The dental office, with particular focus on patients with severe periodontitis, proved to be a suitable location for screening for (pre)diabetes; a considerable number of suspected new diabetes cases were identified. The early diagnosis and treatment of ( pre)diabetes help to prevent more severe complications and benefit the treatment of periodontitis.

\section{INTRODUCTION}

Diabetes mellitus is a growing health problem and its prevalence is dramatically increasing. ${ }^{1}$ The prevalence of diabetes was
Significance of the study

What is already known about this subject?

The early diagnosis of (pre)diabetes mellitus is essential for the prevention of diabetes complications. Periodontitis may be a first sign of diabetes type 2.

\section{What are the new findings?}

On average, patients with periodontitis showed higher glycated hemoglobin (HbA1c) plasma levels compared with individuals without periodontitis. Among the subjects with severe periodontitis whose metabolic status was unknown, $18 \%$ of suspected new diabetes cases were identified.

How might these results change the focus of research or clinical practice?

Here, we show that periodontitis is an early sign of diabetes mellitus and may therefore serve as a valuable risk indicator. A dental office that treats patients with periodontitis is a suitable location for screening for diabetes by a simple finger stick and validated $\mathrm{HbA1c}$ dry spot analysis.

estimated at 285 million adults worldwide in $2010^{2}$ and this is expected to rise to 552 million by $2030 .{ }^{3}$ However, owing to the absence of symptoms and/or disease-related knowledge, diabetes often goes undetected, and approximately one-third of people with diabetes are not aware of their status. ${ }^{4}$ The early diagnosis and intervention of (pre)diabetes prevent the common microvascular and macrovascular complications ${ }^{6}$ and are cost-effective. ${ }^{7}$ Therefore, risk indicators for (pre)diabetes screening are needed and proposed. ${ }^{8}$ In this respect, the onset of several oral pathologies might be indicative of metabolic dysregulation.

Several studies demonstrate the association between diabetes and oral diseases. The most commonly observed chronic oral disease is periodontitis. Periodontitis is a common chronic multifactorial inflammatory disease of the supporting structures of the teeth (root cementum, gingiva, periodontal ligament, and alveolar bone), initiated and sustained by an aberrant host immune response 
against resident bacterial biofilm on the teeth. It is a major cause of tooth loss. ${ }^{9}$ The severe form of this condition occurs in $\sim 10-15 \%$ of the population, and the prevalence is twice as high in subjects $>50$ years of age. ${ }^{10-12}$ Many studies have demonstrated that diabetes mellitus severely exacerbates the onset, progression, and severity of periodontitis. ${ }^{13-16}$ The prevalence of periodontitis in patients with diabetes is estimated to be two or even three times higher than in an otherwise healthy population. ${ }^{17}$ In addition, periodontitis is strongly associated with uncontrolled diabetes mellitus. ${ }^{18} 19$ This is because subjects with diabetes, particularly subjects with uncontrolled diabetes, are more susceptible to infections and impaired wound healing; ${ }^{20}$ therefore, periodontitis is considered to be a complication of diabetes mellitus. ${ }^{14} 2122$ With this knowledge, it has been suggested that dentists could help screen for (pre)diabetes. ${ }^{23} 24$ The majority of dental practices are not equipped for blood biochemistry. The measurements of glycated hemoglobin (HbA1c) using dry blood spots may be a conservative way to screen for diabetes in patients with periodontitis.

The aim of the present study was to determine HbAlc levels and affirm the presence of (pre)diabetes in subjects from a university dental clinic with and without periodontitis using the analysis of dry blood spots. Since periodontitis can be considered a complication of (pre) diabetes, we suggest the hypothesis that patients with periodontitis show an increased prevalence of (pre)diabetes compared with subjects without periodontal disease.

\section{RESEARCH DESIGN AND METHODS Study population}

A consecutive series of patients with periodontitis who were referred to the Department of Periodontology of the Academic Centre for Dentistry Amsterdam (ACTA) for the diagnosis and treatment of periodontitis were enrolled in this study. Controls were selected among subjects registered for restorative dental procedures or those who visited the dental school for regular dental checkups. The selection period was between February 2014 and September 2015. A total of 313 subjects, including 78 patients with severe periodontitis, 126 patients with mild/ moderate periodontitis, and 109 controls, were included in this study. Briefly, referred patients with periodontitis were recruited during their first visit to the periodontal clinic. Probing pocket depth (PPD) measurements and gingival recession (GR), if present, were recorded at six sites per tooth and dental radiographs were available to analyze interproximal alveolar bone levels. For those sites where the GR was recorded, the clinical attachment loss (CAL) could be determined (PPD+GR). Patients were classified as suffering from periodontitis using the Centers for Disease Control and Prevention-American Academy of Periodontology (CDC-AAP) case definition: ${ }^{25}$ mild periodontitis was defined as two or more interproximal sites with $\mathrm{CAL} \geq 3 \mathrm{~mm}$ and two or more interproximal sites with $\mathrm{PPD} \geq 4 \mathrm{~mm}$ (not on the same tooth) or one site with $\mathrm{PPD} \geq 5 \mathrm{~mm}$. Moderate periodontitis was defined as two or more interproximal sites with $\mathrm{CAL} \geq 4 \mathrm{~mm}$ (not on the same tooth) or two or more interproximal sites with $\mathrm{PPD} \geq 5 \mathrm{~mm}$ (not on the same tooth). ${ }^{25}$ Patients who showed at least two interproximal sites with $\mathrm{CAL} \geq 6 \mathrm{~mm}$ on different teeth in conjunction with at least one interproximal site with $\mathrm{PPD} \geq 5 \mathrm{~mm}$ were classified as suffering from severe periodontitis. ${ }^{25}$ All patients were untreated and showed generalized bleeding on probing. Control subjects were included if they did not fulfill any of the aforementioned criteria for case definition. In addition, these subjects showed no interproximal alveolar bone loss on $\leq 1$-year-old dental bitewing radiographs. Subjects with an age of $<18$ years were excluded from the study. No other exclusion criteria were used.

All participants received verbal and written information about the purpose of the study and provided informed consent. The Medical Ethical Committee of the VU University Medical Center approved the study.

\section{Background and diabetes-related characteristics}

For all participants, general and diabetes-related characteristics were recorded with the help of a questionnaire and medical history $(\mathrm{Hx})$. The recorded characteristics were from the questionnaire: sex, age, ethnicity (origin of parents), education level, smoking habits, relatives with diabetes mellitus and a history of periodontal treatment; from the Hx: diagnosis of hypertension, hypercholesterolaemia, and diabetes mellitus. Height and weight were measured in our clinic to determine the body mass index (BMI).

\section{Blood collection and HbA1c analysis}

After a finger-stick, two drops of capillary blood were spotted on a Whatman 903 paper collection card (GE Healthcare Life Sciences, Eindhoven, Netherlands). The collection cards were stored at $4^{\circ} \mathrm{C}$ and sent weekly by regular postal mail to the Clinical Chemistry Laboratory of the Medical Center (MC) Slotervaart, Amsterdam, the Netherlands. Two $6 \mathrm{~mm}$ punches were incubated in $400 \mu \mathrm{L}$ hemolysis buffer of the standard HbA1c test, which was measured immunoturbidimetrically on an Abbott ci8200 clinical chemistry analyzer (Abbott Laboratories, Abbott Park, Illinois, USA). ${ }^{26}$ The finger-stick and Whatman paper collection method was previously validated against the conventional EDTA blood collection by venipuncture according to the Clinical and Laboratory Standards Institute (CLSI) EP9 method comparison protocol. Precision and stability studies of HbA1c on Whatman 903 collection cards have been reported ${ }^{27}$ and showed that the finger-stick collection card and punch method for HbAlc determination was highly correlated with the standard EDTA blood collection method (regression analysis $\mathrm{r}=0.99$; see online supplementary figure $\mathrm{S} 1$ ). To further determine the validity of the finger-stick method in the 
current study population, 10 patients were selected for both the finger-stick analysis and the standard EDTA venous blood collection method. A similar correlation in HbAlc between these two methods was obtained $(r=0.99$, data not shown).

\section{Statistical analyses}

Sample size was determined based on a pilot study, including 49 periodontally healthy subjects and 33 patients with periodontitis. We detected a mean difference in the HbAlc of $0.7 \%(7 \mathrm{mmol} / \mathrm{mol})$ between patients with periodontitis and control subjects, which we considered clinically relevant. The calculation of sample size (http://powerandsamplesize.com) was based on a two-sided Student's t-test of 5\% with $80 \%$ power and using the mean of HbAlc of both groups (control: $5.5 \%(37 \mathrm{mmol} / \mathrm{mol})$ and periodontitis: $6.2 \%$ $(44 \mathrm{mmol} / \mathrm{mol}))$ and an overall study population-based $\mathrm{SD}$ of $1.3 \%(15 \mathrm{mmol} / \mathrm{mol})$. The required sample size was a minimum of 61 subjects per group.

Data were analyzed with SPSS 23.0.0.2 (IBM SPSS, Chicago, Illinois, USA). The means, SDs, medians, total range, and frequency distributions were calculated. According to the American Diabetes Association (ADA) guidelines, ${ }^{8}$ HbAlc values were classified as normal $(<5.7 \% \quad(<39 \mathrm{mmol} / \mathrm{mol}))$, pre-diabetes $(5.7-6.4 \% \quad(39-$ $47 \mathrm{mmol} / \mathrm{mol}))$, or diabetes mellitus $(\geq 6.5 \%$ $(\geq 48 \mathrm{mmol} / \mathrm{mol}))$. The general and diabetes-related characteristics of the study population, HbAlc levels, and (pre)diabetes prevalence within the study population were compared with parametric and nonparametric tests (analysis of variance (ANOVA) and $\chi^{2}$ test). Where applicable, analyses were corrected for multiple testing (Bonferroni). For all analyses, the significance level was set to $\mathrm{p}<0.05$.

\section{RESULTS}

\section{Study population}

In this study, a total of 313 consecutive subjects (109 controls, 126 patients with mild/moderate and 78 patients with severe periodontitis) were included. Demographic and diabetes-related characteristics of the study population are presented in table 1 . The mean ages for the control, mild/moderate, and severe periodontitis groups were $48.4,51.1$, and 50.5 years, respectively $(p=0.200)$. Overall differences in sex distribution between the groups were significant $(\mathrm{p}=0.010)$, with more males in the severe group (62\% compared with $40 \%$ in the mild/moderate periodontitis group and $47 \%$ in the control group). In addition, more subjects from the control group were in the highest education category compared with the periodontitis groups $(\mathrm{p}=0.007)$. Among patients with periodontitis, there were more current smokers (mild/moderate periodontitis: $23.0 \%$ and severe periodontitis: $37.2 \%$ ), while this rate was $9.2 \%$ among controls $(\mathrm{p}<0.001)$.
The BMI was significantly higher in patients with periodontitis $\left(\geq 27 \mathrm{~kg} / \mathrm{m}^{2}\right)$ than in controls $\left(24.9 \mathrm{~kg} / \mathrm{m}^{2}\right)$, and more patients in the periodontitis group could be classified as being overweight (BMI $\geq 25 \mathrm{~kg} / \mathrm{m}^{2}$; $p=0.008$ ). No significant differences could be observed between the three groups regarding the number of subjects reporting hypertension and hypercholesterolaemia, while patients with more mild/moderate periodontitis reported relatives with diabetes mellitus. The number of individuals with self-reported diabetes mellitus was not significantly different between the controls and patients with periodontitis (2.8\% for controls, $4.0 \%$ for mild/ moderate periodontitis, and $7.7 \%$ for severe periodontitis, $\mathrm{p}=0.256$, table 2 ).

Patients with periodontitis had significantly fewer teeth than controls $(\mathrm{p}<0.001)$, and the severe periodontitis group had more teeth with $\geq 50 \%$ alveolar bone loss than the mild/moderate periodontitis group (median: 8 and 1, respectively). Controls had no alveolar bone loss.

\section{HbA1c analysis}

The mean HbAlc values for the study groups are presented in table 2. With an increasing severity of periodontitis, a significant increase in HbAlc levels could be observed $(p=0.003)$. On average, the mean HbAlc in the severe periodontitis group was $6.3 \%(45 \mathrm{mmol} /$ $\mathrm{mol})$, in the mild/moderate periodontitis group, $6.1 \%$ $(43 \mathrm{mmol} / \mathrm{mol})$, and in the controls, $5.7 \%(39 \mathrm{mmol} /$ $\mathrm{mol})$. Subsequently, we tabulated the number of subjects with suspected diabetes and pre-diabetes based on levels of HbAlc using the ADA guidelines. ${ }^{8}$ There was a significant over-representation of subjects with suspected diabetes $(23 \%$ and $14 \%)$ and pre-diabetes $(47 \%$ and $46 \%)$ in the severe periodontitis group and mild/moderate periodontitis groups, respectively, compared with the control group (10\% and $37 \%$, table 2).

The ADA HbAlc cut-off for diabetes $(6.5 \%$, $(48 \mathrm{mmol} / \mathrm{mol})$ ) might explain the relatively high prevalence of suspected diabetes in the control group (10\%) compared with the estimated overall prevalence of diabetes in the Netherlands (5\%). ${ }^{28}$ Since a threshold of HbAlc of $7 \%(53 \mathrm{mmol} / \mathrm{mol})$ has been proposed to exclude possible false-positive measurements, ${ }^{29}{ }^{30}$ the prevalence of study subjects with $\mathrm{HbAlc} \geq 7 \%$ ( $\geq 53 \mathrm{mmol} / \mathrm{mol}$ ) was determined: control, $3.7 \%$; mild/ moderate periodontitis, $7.1 \%$; and severe periodontitis, $12.8 \%(\mathrm{p}=0.061)$.

To further explore the potential role of periodontitis as a risk indicator for diabetes and its contribution to diabetes screening, we determined the percentage of patients without an $\mathrm{Hx}$ of diabetes that had an HbAlc $\geq 6.5 \%(\geq 48 \mathrm{mmol} / \mathrm{mol}$, new diabetes $)$. In all groups, patients with suspected new diabetes were found, and this number increased with increasing severity of periodontitis (control: $8.5 \%$, mild/moderate periodontitis: $9.9 \%$, and severe periodontitis: $18.1 \%$, $\mathrm{p}=0.024$, table 2). 
Table 1 Background characteristics

\begin{tabular}{|c|c|c|c|c|}
\hline & $\begin{array}{l}\text { Control } \\
(n=109)\end{array}$ & $\begin{array}{l}\text { Mild/moderate periodontitis } \\
(n=126)\end{array}$ & $\begin{array}{l}\text { Severe periodontitis } \\
(n=78)\end{array}$ & p Value \\
\hline Age (years) & $48.4 \pm 14.8$ & $51.1 \pm 11.5$ & $50.5 \pm 10.1$ & 0.200 \\
\hline Sex, male (\%) & $51(46.8 \%)$ & $50(39.7 \%)$ & $48(61.5 \%)$ & 0.010 \\
\hline Origin, European (\%) & $84(77.1 \%)$ & $94(74.6 \%)$ & $53(67.9 \%)$ & 0.364 \\
\hline Education (\%) & & & & 0.007 \\
\hline Low & $13(11.9 \%)$ & $28(22.2 \%)$ & $21(26.9 \%)$ & \\
\hline Medium & $30(27.5 \%)$ & $47(37.3 \%)$ & 27 (34.6\%) & \\
\hline High & $66(60.6 \%)$ & $51(40.5 \%)$ & $30(38.5 \%)$ & \\
\hline BMI $\left(\mathrm{kg} / \mathrm{m}^{2}\right)$ & $24.9 \pm 3.7$ & $27.2 \pm 4.6^{\star}$ & $27.0 \pm 4.7^{\star}$ & 0.000 \\
\hline $\mathrm{BMI} \geq 25 \mathrm{~kg} / \mathrm{m}^{2}(\%)$ & $48(44.0 \%)$ & $80(63.5 \%)$ & $47(60.3 \%)$ & 0.008 \\
\hline Smoking status (\%) & & & & 0.000 \\
\hline Never & $62(56.9 \%)$ & $34(27.0 \%)$ & $12(15.4 \%)$ & \\
\hline Former & 37 (33.9\%) & $63(50.0 \%)$ & 37 (47.4\%) & \\
\hline Current & $10(9.2 \%)$ & $29(23.0 \%)$ & $29(37.2 \%)$ & \\
\hline Hypertension (\%)† & $23(21.1 \%)$ & $24(19.0 \%)$ & $14(17.9 \%)$ & 0.855 \\
\hline Hypercholesterolemia† & $16(14.7 \%)$ & $22(17.5 \%)$ & $17(21.8 \%)$ & 0.451 \\
\hline First-degree relative with diabetes (\%) & $40(36.7 \%)$ & $71(56.3 \%)$ & $28(35.9 \%)$ & 0.002 \\
\hline Number of teeth & $28(20-32)$ & $27(16-32)^{*}$ & $26(15-32)^{*} \ddagger$ & 0.000 \\
\hline Number of teeth with $\geq 50 \%$ bone loss & NA & $1(0-6) \S$ & $8(0-23) \uparrow$ & 0.000 \\
\hline Number of teeth with PPD $\geq 6 \mathrm{~mm}$ & NA & $4(0-22)$ & $16(1-32)$ & 0.000 \\
\hline Number of sites with PPD $\geq 6 \mathrm{~mm}$ & NA & $7.5(0-71)$ & $44.5(1-115)$ & 0.000 \\
\hline \multicolumn{5}{|c|}{$\begin{array}{l}\text { Data are presented as the mean } \pm S D \text {, median, and range, or as } n(\%) \text {. } \\
\text { *Bonferroni test: } p \text { value }<0.05 \text { compared with control. } \\
\text { †Based on the medical history }(\mathrm{Hx}) \text {. } \\
\text { †Bonferroni test: } p \text { value }<0.05 \text { compared with mild/moderate periodontitis. } \\
\S n=122 \text {. } \\
\text { In }=72 \text {. } \\
\text { BMI, body mass index; NA, not applicable; PPD, probing pocket depth. }\end{array}$} \\
\hline
\end{tabular}

Table $2 \mathrm{HbA1c}$ values and the suspected diagnosis of (pre)diabetes* in patients with and without diabetes based on medical history

\begin{tabular}{|c|c|c|c|c|}
\hline & Control $(n=109)$ & $\begin{array}{l}\text { Mild/moderate } \\
\text { periodontitis }(n=126)\end{array}$ & $\begin{array}{l}\text { Severe periodontitis } \\
(n=78)\end{array}$ & p Value \\
\hline Diabetes, $\mathrm{Hx}(\%) \dagger$ & $3(2.8 \%)$ & $5(4.0 \%)$ & $6(7.7 \%)$ & 0.256 \\
\hline \multicolumn{5}{|l|}{$\mathrm{HbA1c}(\%)(\mathrm{mmol} / \mathrm{mol})$} \\
\hline All subjectsł & $5.7 \pm 0.7(39 \pm 8)$ & $6.1 \pm 1.4(43 \pm 15)$ & $6.3 \pm 1.3 \S(45 \pm 15)$ & 0.003 \\
\hline Subjects without diabetes $\prod^{\star *}$ & $5.7 \pm 0.6(38 \pm 7)$ & $6.0 \pm 1.3(42 \pm 15)$ & $6.2 \pm 1.2 \S(44 \pm 13)$ & 0.009 \\
\hline \multicolumn{5}{|c|}{ Number of suspected diagnosis (\%) } \\
\hline All subjects $\ddagger$ & & & & 0.010 \\
\hline Healthy & $58(53.2 \%)$ & $51(40.5 \%)$ & $23(29.5 \%)$ & \\
\hline Pre-diabetes & $40(36.7 \%)$ & $58(46.0 \%)$ & $37(47.4 \%)$ & \\
\hline Diabetes & $11(10.1 \%)$ & $17(13.5 \%)$ & $18(23.1 \%)$ & \\
\hline Subjects without diabetes $\prod^{\star *}$ & & & & 0.024 \\
\hline Healthy & $58(54.7 \%)$ & $51(42.1 \%)$ & $23(31.9 \%)$ & \\
\hline Pre-diabetes & $39(36.8 \%)$ & $58(47.9 \%)$ & $36(50.0 \%)$ & \\
\hline Diabetes & $9(8.5 \%)$ & $12(9.9 \%)$ & $13(18.1 \%)$ & \\
\hline
\end{tabular}

Data are presented as the mean \pm SD or as $n(\%)$.

*(Pre)diabetes classification according to the ADA guidelines 2015.

†Based on the medical history $(\mathrm{Hx})$.

¥Subjects with and without diabetes based on the medical history are included.

$\S$ Bonferroni test: $p$ value $<0.05$ compared with control.

TSubjects with diabetes based on the medical history are excluded.

${ }^{* *}$ Control: $n=106$; mild/moderate periodontitis: $n=121$; severe periodontitis: $n=72$.

ADA, American Diabetes Association; HbA1c, glycated hemoglobin. 


\section{CONCLUSIONS}

In this study, we aimed to evaluate HbAlc values in subjects without and with periodontitis to establish the prevalence of (pre)diabetes, as periodontitis has been considered a complication of (pre) diabetes. ${ }^{14}$ This study used a validated finger-stick test for HbAlc with the advantage of a chairside test and the accuracy of the standard immunoturbidimetric assessment of HbAlc on a clinical analyzer applying the new ADA guidelines for the diagnosis of diabetes. ${ }^{8}$ Therefore, this method is very useful for the screening of (pre)diabetes in a dental office setting. The idea of diabetes screening in the dental office has been suggested by several other research groups, although their reports may have had different aims and techniques among themselves. ${ }^{23}$ 31-34 The early identification of subjects at high risk for (pre) diabetes mellitus or with undiagnosed diabetes mellitus is crucial to implement measures that may prevent or delay progression from pre-diabetes to overt diabetes mellitus and reduce the incidence of chronic complications. ${ }^{35}$ For example, the results of a 20-year follow-up study showed that early prevention strategies, such as lifestyle intervention, resulted in a reduction in diabetes mellitus onset and consequently, it was associated with a $47 \%$ reduction in the incidence of threatening retinopathy. ${ }^{36}$ Recently, a 23-year follow-up of the latter study showed that early lifestyle intervention was associated with a decrease in the cumulative incidence of cardiovascular and all-cause mortality. ${ }^{37}$ Current ADA recommendations for the management of (pre)diabetes reflect these observations and risk indicators for (pre)diabetes screening are needed and proposed. ${ }^{8}$ Notably, among subjects with severe periodontitis, we found that more than $18 \%$ of the subjects, who were unaware of the presence of diabetes, had HbAlc values exceeding the 6.5\% ( $48 \mathrm{mmol} / \mathrm{mol}$ ) threshold. This proportion is almost two times greater than those observed for patients with mild/moderate periodontitis $(9.9 \%)$ and for subjects without periodontitis $(8.5 \%)$. This confirms the assumption that severe periodontitis could be an early sign of undiagnosed diabetes. In this respect, the presence of severe periodontitis might be indicative of metabolic dysregulation and by the identification of diabetes, treatment of this disease can be initiated, which is also relevant for the successful treatment of periodontitis. We expect that a good collaboration between dentists and diabetologists will lead to the best treatment results.

One recent study used a point-of-care (POC) HbA1c assessment by means of a finger-stick blood sample but employed a benchtop analyzer. ${ }^{38}$ Although this test obtains rapid results, the accuracy compared with values obtained by the standard assessment of HbAlc is questionable. ${ }^{39}$ In contrast, our finger-stick and Whatman paper collection method and the standard immunoturbidimetric assessment of HbAlc on an Abbott ci8200 clinical chemistry analyzer ${ }^{26}$ showed a very high correlation with the venipuncture collection method and subsequent HbA1c measurement $(r=0.99)$. Despite a less accurate $\mathrm{HbA1c}$ determination, the results of the recent study $^{38}$ corroborate our findings that a substantial number of patients with suspected new diabetes in the periodontitis group can be found. A higher frequency of patients with suspected new diabetes in the periodontitis group in our study can be explained by the higher accuracy of our method for HbAlc determination and a clear case definition for subjects without or with mild/moderate or severe periodontitis. Notably, subjects with severe periodontitis showed a high frequency of suspected new diabetes cases, and the applied ADA case definition may therefore be very useful in general practice. In our study, compared with the recent publication, ${ }^{38}$ the control and periodontitis groups were comparable regarding age and ethnic origin; these factors have been considered important for diabetes screening. ${ }^{8}$

The prevalence of suspected diabetes in the control group $(10.1 \%)$ in this study, as measured by HbAlc, is high compared with the overall estimated prevalence in the Netherlands $(5.45 \%) .{ }^{28}$ An obvious explanation could be that our study population, derived from a dental school, is not representative of the Dutch population. Another reason might be that the national prevalence is actually an underestimation; since diabetes is often asymptomatic in its early stages, it may remain undiagnosed for many years. ${ }^{40}$ In addition, it is possible that the current use of HbAlc levels results in a higher prevalence compared with the prevalence based on the traditional parameter plasma glucose levels, such as fasting plasma glucose levels and/or the oral glucose tolerance test. The recently adopted diagnosis of diabetes by $\mathrm{HbAlc}$ has been proposed by the $\mathrm{ADA},{ }^{8}$ and the advantages and disadvantages for $\mathrm{HbAlc}$ as a diagnostic marker have been extensively discussed in the literature. ${ }^{30} 41-45$ However, most of the studies show that even the use of HbAlc levels may result in an underestimation of diabetes prevalence. Nevertheless, a higher cut-off of HbAlc of $\geq 7.0 \%$ ( $\geq 53 \mathrm{mmol} / \mathrm{mol}$, instead of $\geq 6.5 \%(\geq 48 \mathrm{mmol} / \mathrm{mol})$ ) has been proposed to exclude a possible false-positive diagnosis. ${ }^{29} 30$ When applying this threshold, the prevalence of subjects with $\mathrm{HbAlc}$ levels of $\geq 7.0 \%(\geq 53 \mathrm{mmol} / \mathrm{mol})$ in the control group was $3.7 \%$, and this can be considered to be in agreement with the overall estimated prevalence of diabetes in the Netherlands. Nevertheless, applying the threshold $\geq 7 \%(\geq 53 \mathrm{mmol} / \mathrm{mol})$, the prevalence of subjects with diabetes was clearly higher in those with mild/ moderate periodontitis $(7.1 \%)$ and with severe periodontitis $(12.8 \%)$. Interestingly, the results show that half of the subjects classified as having diabetes, using a threshold of $\geq 6.5 \%(\geq 48 \mathrm{mmol} / \mathrm{mol})$, do have HbAlc levels in the range of $6.5-7 \%(48-53 \mathrm{mmol} / \mathrm{mol})$, confirming that periodontitis is a useful risk indicator for the screening of early diabetes. The early diagnosis and intervention of (pre)diabetes prevent the common microvascular and macrovascular complications ${ }^{6}$ and are cost-effective. ${ }^{7}$ In addition, it can be suggested that the early diagnosis and treatment of ( pre) diabetes may also benefit the treatment of periodontitis. 
A dental office that treats patients with severe periodontitis is a suitable location for screening for (pre) diabetes; a considerable number of suspected new diabetes cases were identified and indicated that periodontitis is an early sign of diabetes mellitus.

Contributors WJT and BGL designed the study, analyzed the data, and wrote the manuscript. MXFK designed the study, analyzed the data, and contributed to the discussion. DCWP and VEAG designed the study, contributed to the discussion, and reviewed and edited the manuscript.

Funding This research was supported in part by a grant from the University of Amsterdam for the focal point 'Oral Infection and Inflammation'.

Competing interests None declared.

Ethics approval The Medical Ethical Committee of the VU University Medical Center approved the study.

Provenance and peer review Not commissioned; externally peer reviewed.

Data sharing statement No additional data are available.

Open Access This is an Open Access article distributed in accordance with the Creative Commons Attribution Non Commercial (CC BY-NC 4.0) license, which permits others to distribute, remix, adapt, build upon this work noncommercially, and license their derivative works on different terms, provided the original work is properly cited and the use is non-commercial. See: http:// creativecommons.org/licenses/by-nc/4.0/

\section{REFERENCES}

1. Lam DW, LeRoith D. The worldwide diabetes epidemic. Curr Opin Endocrinol Diabetes Obes 2012;19:93-6.

2. Shaw JE, Sicree RA, Zimmet PZ. Global estimates of the prevalence of diabetes for 2010 and 2030. Diabetes Res Clin Pract 2010;87:4-14.

3. Whiting DR, Guariguata L, Weil C, et al. IDF diabetes atlas: global estimates of the prevalence of diabetes for 2011 and 2030. Diabetes Res Clin Pract 2011;94:311-21.

4. Cowie CC, Rust KF, Byrd-Holt DD, et al. Prevalence of diabetes and impaired fasting glucose in adults in the U.S. population: National Health and Nutrition Examination Survey 1999-2002. Diabetes Care 2006;29:1263-8.

5. Kim SM, Lee JS, Lee J, et al. Prevalence of diabetes and impaired fasting glucose in Korea: Korean National Health and Nutrition Survey 2001. Diabetes Care 2006;29:226-31.

6. Tian L, Zhu J, Liu L, et al. Prediabetes and short-term outcomes in nondiabetic patients after acute ST-elevation myocardial infarction. Cardiology 2014;127:55-61.

7. Herman WH, Hoerger TJ, Brandle M, et al. The cost-effectiveness of lifestyle modification or metformin in preventing type 2 diabetes in adults with impaired glucose tolerance. Ann Intern Med 2005;142:323-32.

8. American Diabetes Association. Classification and diagnosis of diabetes. Diabetes Care 2015;(Suppl 38):S8-16.

9. Pihlstrom BL, Michalowicz BS, Johnson NW. Periodontal diseases. Lancet 2005;366:1809-20.

10. Burt B. Research Science and Therapy Committee of the American Academy of Periodontology. Position paper: epidemiology of periodontal diseases. J Periodontol 2005;76:1406-19.

11. Eke PI, Thornton-Evans G, Dye B, et al. Advances in surveillance of periodontitis: the Centers for Disease Control and Prevention periodontal disease surveillance project. $J$ Periodontol 2012;83:1337-42.

12. Hugoson $A$, Norderyd $O$. Has the prevalence of periodontitis changed during the last 30 years? J Clin Periodontol 2008;35(Suppl 8):338-45.

13. Demmer RT, Holtfreter B, Desvarieux M, et al. The influence of type 1 and type 2 diabetes on periodontal disease progression: prospective results from the Study of Health in Pomerania (SHIP). Diabetes Care 2012;35:2036-42.

14. Lalla E, Papapanou PN. Diabetes mellitus and periodontitis: a tale of two common interrelated diseases. Nat Rev Endocrinol 2011;7:738-48

15. Mealey BL, Rose LF. Diabetes mellitus and inflammatory periodontal diseases. Curr Opin Endocrinol Diabetes Obes 2008;15:135-41.
16. Taylor GW, Borgnakke WS. Periodontal disease: associations with diabetes, glycemic control and complications. Oral Dis 2008;14:191-203.

17. Mealey BL, Oates TW. American Academy of Periodontology Diabetes mellitus and periodontal diseases. J Periodontol 2006;77:1289-303.

18. Garcia D, Tarima S, Okunseri C. Periodontitis and glycemic control in diabetes: NHANES 2009 to 2012. J Periodontol 2015;86:499-506.

19. Eke PI, Wei L, Thornton-Evans GO, et al. Risk indicators for periodontitis in US adults: NHANES 2009 to 2012. J Periodontol 2016;87:1174-85.

20. Muller LM, Gorter KJ, Hak E, et al. Increased risk of common infections in patients with type 1 and type 2 diabetes mellitus. Clin Infect Dis 2005;41:281-8.

21. Loe H. Periodontal disease. The sixth complication of diabetes mellitus. Diabetes Care 1993;16:329-34.

22. Preshaw PM, Alba AL, Herrera D, et al. Periodontitis and diabetes: a two-way relationship. Diabetologia 2012;55:21-31.

23. Lalla E, Kunzel C, Burkett S, et al. Identification of unrecognized diabetes and pre-diabetes in a dental setting. $J$ Dent Res 2011;90:855-60.

24. Strauss SM, Russell S, Wheeler A, et al. The dental office visit as a potential opportunity for diabetes screening: an analysis using NHANES 2003-2004 data. J Public Health Dent 2010;70:156-62.

25. Eke PI, Page RC, Wei L, et al. Update of the case definitions for population-based surveillance of periodontitis. J Periodontol 2012;83:1449-54.

26. Elefano EC, Jabeen $\mathrm{R}$, Onifade $\mathrm{K}$, et al. Analytical evaluation of HgbA1c, microalbumin, CRP, and RF on Architect ci8200 integrated system and workflow performance evaluation using computer simulation. Clin Chim Acta 2006;366:204-8.

27. Fokkema MR, Bakker AJ, de Boer F, et al. HbA1c measurements from dried blood spots: validation and patient satisfaction. Clin Chem Lab Med 2009;47:1259-64.

28. Kleefstra N, Landman GW, Van Hateren KJ, et al. Dutch diabetes prevalence estimates (DUDE-1). J Diabetes 2016;8:863-5.

29. Saudek CD, Herman WH, Sacks DB, et al. A new look at screening and diagnosing diabetes mellitus. J Clin Endocrinol Metab 2008;93:2447-53.

30. van 't Riet E, Alssema M, Rijkelijkhuizen JM, et al. Relationship between $\mathrm{A} 1 \mathrm{C}$ and glucose levels in the general Dutch population: the new Hoorn study. Diabetes Care 2010;33:61-6.

31. Lalla E, Cheng B, Kunzel C, et al. Six-month outcomes in dental patients identified with hyperglycaemia: a randomized clinical trial. $\mathrm{J}$ Clin Periodontol 2015;42:228-35.

32. Lalla E, Cheng B, Kunzel C, et al. Dental findings and identification of undiagnosed hyperglycemia. J Dent Res 2013;92:888-92.

33. Rosedale MT, Strauss SM, Kaur N, et al. Follow-up with primary care providers for elevated glycated haemoglobin identified at the dental visit. Int J Dent Hyg 2016. doi:10.1111/idh.12214. [Epub ahead of print March 2016]

34. Strauss SM, Rosedale MT, Pesce MA, et al. The potential for glycemic control monitoring and screening for diabetes at dental visits using oral blood. Am J Public Health 2015;105:796-801.

35. Bianchi C, Miccoli R, Bonadonna RC, et al. Pathogenetic mechanisms and cardiovascular risk: differences between $\mathrm{HbA}(1 \mathrm{c})$ and oral glucose tolerance test for the diagnosis of glucose tolerance. Diabetes Care 2012;35:2607-12.

36. Gong Q, Gregg EW, Wang J, et al. Long-term effects of a randomised trial of a 6-year lifestyle intervention in impaired glucose tolerance on diabetes-related microvascular complications: the China Da Qing Diabetes Prevention Outcome Study. Diabetologia 2011:54:300-7.

37. Li G, Zhang P, Wang J, et al. Cardiovascular mortality, all-cause mortality, and diabetes incidence after lifestyle intervention for people with impaired glucose tolerance in the Da Qing Diabetes Prevention Study: a 23-year follow-up study. Lancet Diabetes Endocrinol 2014;2:474-80.

38. Holm NC, Belstrøm D, Østergaard JA, et al. Identification of individuals with undiagnosed diabetes and pre-diabetes in a Danish cohort attending dental treatment. $J$ Periodontol 2016;87:395-402.

39. Manley SE, Hikin LJ, Round RA, et al. Comparison of IFCC-calibrated $\mathrm{HbA}(1 \mathrm{c})$ from laboratory and point of care testing systems. Diabetes Res Clin Pract 2014;105:364-72.

40. Harris MI, Klein R, Welborn TA, et al. Onset of NIDDM occurs at least $4-7$ yr before clinical diagnosis. Diabetes Care 1992;15:815-19. 
41. Carson AP, Reynolds K, Fonseca VA, et al. Comparison of A1C and fasting glucose criteria to diagnose diabetes among U.S. adults. Diabetes Care 2010;33:95-7.

42. Christensen DL, Witte DR, Kaduka L, et al. Moving to an A1C-based diagnosis of diabetes has a different impact on prevalence in different ethnic groups. Diabetes Care 2010;33:580-2.

43. Kramer CK, Araneta MR, Barrett-Connor E. A1C and diabetes diagnosis: the Rancho Bernardo study. Diabetes Care 2010;33:101-3.
44. Lorenzo C, Haffner SM. Performance characteristics of the new definition of diabetes: the insulin resistance atherosclerosis study. Diabetes Care 2010;33:335-7.

45. Zhou X, Pang Z, Gao W, et al. Performance of an A1C and fasting capillary blood glucose test for screening newly diagnosed diabetes and pre-diabetes defined by an oral glucose tolerance test in Qingdao, China. Diabetes Care 2010;33:545-50. 